\title{
New Nanoscale Polymer Systems And Their Interaction With Living Objects
}

\author{
M.I.Shtilman ${ }^{*}$, A.N.Kuskov ${ }^{1}$, P.P.Kulikov ${ }^{1}$, A.L.Luss ${ }^{1}$, A.V.Goryachaya, \\ V.T.Dzhedzheyal, S.A. Gusev², P.Henrich-Noack ${ }^{3}$,L.Gurevich', V.P.Torchilin', \\ A.M.Tsatsakis ${ }^{6}$
}

${ }^{1}$ D.I.Mendeleyev University of Chemical Technology of Russian, Department of Biomaterials.

Moscow, Russia. E-mail shtilmanm@yandex.ru

${ }^{2}$ Clinical Center for Physical-Chemical Medicine, Moscow, Russia

${ }^{3}$ Institute of Medical Psychology, Otto-von-Guericke University, Magdeburg, Germany

${ }^{4}$ Aalborg University, Aalborg, Denmark

${ }^{5}$ Center for Pharmaceutical Biotechnology and Nanomedicine, Northeastern University, Boston, MA 02115, USA

${ }^{6}$ University of Crete, Medical School, Division Morphology, Greece

The synthesis methods and properties of amphiphilic polymers of $\mathrm{N}$-vinylpyrrolidone, acrylamide, acrylic acid were studied and it was shown that these systems can be used for modification of liposomal membranes and as micelles-like aggregates [1,2].

To the date, methods have been developed for the preparation of nanoparticles based on such polymers with immobilized poorly-soluble or insoluble in water low molecular weight, biologically active compounds, such as indomethacin, diclofenac, amphotericin B, nystatin, 5fluorouracil, rifabutin, felodipine, ionol, curcumin. [3,4].

On the other hand, aggregates of amphiphilic polymers of $\mathrm{N}$-vinylpyrrolidone proved to be suitable for use as carriers of various proteins and peptides (blood factor IX, angiostatin, Bowman-Birk soybean proteinase (BBI). In this case, immobilization with the use of polymeric aggregates increases the resistance of proteins to denaturing effects, and thereof their total biological activity. Introduction of additional side amino groups in the polymeric part of amphiphilic systems allows the use of aggregates as carriers of nucleic acids and their subsequent application for transfection in genetic engineering $[5,6]$.

Using fluorescent labels and probes, it was shown that the immobilized substance introduced into larger size aggregates penetrates into the living cell due to endocytosis, localizing in the cytoplasm inside the endosome. On the other hand, when immobilized matter is introduced in smaller-size aggregates, it evenly spreads both in the cytoplasm of the cell and in its nucleus. When studying the transport of aggregates of amphiphilic polymers of $\mathrm{N}$ vinylpyrrolidone in the body (rats), it was established that a fluorescent probe immobilized in aggregates of amphiphilic polymers, when injected into the tail of experimental animals, quickly reaches the vessels of the eye [7-9].

\section{References.}

[1] V.P.Torchilin, M.I.Shtilman, V.S.Trubetskoy, K Whiteman., Biochimica et Biophysica Acta. Biomembranes N.1195, 181-184 (1994).

[2] V.P.Torchilin, T.S.Levchenko, K.R.Whiteman, A.A.Yaroslavov, Tsatsakis, A.M., A.K.Rizos, E.V.Michailova, M.I. Shtilman Biomaterials. 22, 3035-3044 (2001).

[3] A.N.Kuskov, P.P.Kulikov, A.V.Goryachaya, M.Tzatzarakis, A.O.Docea, K.Velonia, M.I.Shtilman, A.M.Tsatsakis Nanomedicine: Nanotechnology, Biology, and Medicine, 13, 1021-1030 (2017). 
[4] A.N.Kuskov, P.P.Kulikov, A.V.Goryachaya, M.N.Tsatzarakis, A.M.Tsatsakis, K.Velonia, M.I.Shtilman J. Applied Polymer Science 135, 45673 (2018).

[3] C.L.Andersen, S.B.Romme, P.Fojan, C.P.Pennisi, A.L.Luss, P.P.Kulikov, L.Gurevich, M.I. Shtilman Biophysical J. B511, 590 (2017).

[5] A.L.Villemson, A.N.Kuskov, M.I.,Shtilman, L.V.Galebskaya, E.V.Ryumina, N.I. Larionova Biochemistry (Moscow) 69, 765-775 (2004).

[6] O.Klimenko, M.Shtilman Cancer Gene Therapy 20, 237-241 (2013).

[7] A.L.Luss, C.L.Andersen, I.G.Benito, R.C.Marzo, Z.H.Medina, M.B.Rosenlund,

S.B.Romme, P.P.Kulikov, C.P.Pennisi, M.I.Shtilman, L.Gurevich Biophysical J. 114, 278-279 (2018).

[8] A.L.Luss, P.P.Kulikov, S.B.Romme, C.L.Andersen, C.P.Pennisi, A.O.Docea, A.N.Kuskov, K.Velonia, Ya.O.Mezhuev, M.I.Shtilman, A.M.Tsatsakis, L.Gurevich Nanosized carriers based on amphiphilic poly-N-vinyl-2-pyrrolidone for intranuclear drug delivery. Nanomedicine, 13, 703-715 (2018).

[9] M.Tawfik, M.Sokolov, L.Grigartzik, P. Kulikov, A. Kuskov, M. Shtilman, B.A.Sabel, P.Henrich-Noack Bionanotox (Crete, Greece), P02 (2018). 